A) Check for updates

Cite this: Dalton Trans., 2018, 47 8193

Received 6th March 2018, Accepted 25th May 2018

DOI: $10.1039 / c 8 d t 00866 c$

rsc.li/dalton

\section{Comparison of microwave and mechanochemical energy inputs in the catalytic oxidation of cyclohexane $\uparrow$}

\author{
Ana P. C. Ribeiro, (D) ${ }^{a}$ Elisabete C. B. A. Alegria, (D) *a,b Maximilian N. Kopylovich, (D) \\ Ana M. Ferraria, (D) ${ }^{c}$ Ana M. Botelho do Rego (D) ${ }^{c}$ and Armando J. L. Pombeiro (D) *a
}

The effect of microwave and mechanochemical ball milling energy inputs was studied for the peroxidative oxidation (with aqueous $\mathrm{H}_{2} \mathrm{O}_{2}$ ) of cyclohexane to cyclohexanol and cyclohexanone, over $\mathrm{CoCl}_{2}$ and/or $\mathrm{V}_{2} \mathrm{O}_{5}$ dispersed ( $\mu \mathrm{m}$ scale) catalysts. A maximum total yield of cyclohexanol and cyclohexanone of $43 \%$ after $1 \mathrm{~h}$ of reaction at $30{ }^{\circ} \mathrm{C}$, in acetonitrile and under microwave irradiation (5 W), was achieved over the $\mathrm{CoCl}_{2}-\mathrm{V}_{2} \mathrm{O}_{5}(3: 1)$ catalyst prepared by ball milling. Cyclohexanol is the main final product with a selectivity of up to $93 \%$ over cyclohexanone. Conducting the oxidation reaction under microwave irradiation under the same conditions but without any mechanochemical treatment of the catalyst prior to use resulted in a lower total yield of $30 \%$ with a lower selectivity $(69 \%)$ towards cyclohexanol over cyclohexanone. The sole application of mechanochemical treatment for the catalyst preparation and the catalytic oxidation of cyclohexane allowed to reach yields of $29 \%$ after $1 \mathrm{~h}$ of reaction, at room temperature, without microwave irradiation and any additive and in the absence of any organic solvent. Ball milling is shown to provide a convenient, solvent-free method to disperse these solid catalysts and to promote the above cyclohexane oxidation, although, in the latter case, not so effectively as microwave irradiation.

\section{Introduction}

The application of alternative energy inputs, such as microwave or ultrasonic irradiation, is one of the ways to perform effective chemical transformations under mild reaction conditions. ${ }^{1}$ As a result, a number of existing synthetic protocols can be significantly improved in comparison with those performed under con-

\footnotetext{
${ }^{a}$ Centro de Química Estrutural, Instituto Superior Técnico, Universidade de Lisboa, Av. Rovisco Pais, 1049-001 Lisboa, Portugal.E-mail: ebastos@deq.isel.ipt.pt

${ }^{b}$ Chemical Engineering Departament, Instituto Superior de Engenharia de Lisboa, Instituto Politécnico de Lisboa, R. Conselheiro Emídio Navarro, 1, 1959-007 Lisboa, Portugal

${ }^{c}$ Centro de Química-Física Molecular, Institute of Nanoscience and Nanotechnology and IBB-Institute for Bioengineering and Biosciences, Instituto Superior Técnico, Universidade de Lisboa, 1049-001 Lisboa, Portugal

$\dagger$ Electronic supplementary information (ESI) available. See DOI: 10.1039/ c8dt00866c
}

ventional heating. For instance, electromagnetic microwaves (MW) with wavelengths of $1 \mathrm{~mm}-1 \mathrm{~m}$ can directly transfer energy to polar intermediates or catalysts, thus improving the efficiency and decreasing the reaction time. However, the utilization of MW irradiation is not always advantageous due to its rather complicated relationship to the composition of the reaction mixture, the reaction mechanism and a number of other factors. ${ }^{2}$

Reactions can also be promoted by applying mechanical energy, for example, by ball milling (BM). If mechanical grinding is under consideration, the elevated rates of the performed reactions are related to high concentrations of the starting materials, interaction over large areas, formation of point defects and dislocations in the crystal lattices, breaking the order of the crystalline structure, production of new surfaces and cracks, ionic exchange, etc. ${ }^{1 b}$ At the point of collision of edges, the solids deform and melt, forming hot points where the molecules reach high excitation states. ${ }^{1 b}$ However, the energy accumulated in the defects of the crystalline structure can also lead to slower chemical transformations. Hence, mechanochemical processes can significantly differ from those performed under other energy inputs. For example, conventional heating of solid $\mathrm{HgCl}$ and $\mathrm{AgCl}$ leads to their melting and subliming, while their milling results in metal recovery with $\mathrm{Cl}_{2}$ gas evolution. ${ }^{1 b}$

Although the advantageous effects of alternative energy inputs have been well recognized and reviewed during the last decade, ${ }^{1}$ an experimental comparison of microwave and mechanochemical treatments has not yet been intentionally performed for the same catalytic reaction. Hence, we decided to fill this blank and compare microwave and mechanochemical energy inputs in the catalytic oxidation of cyclohexane. We choose this reaction due to our longstanding interest in such a transformation ${ }^{3}$ and its importance in industry. ${ }^{4}$

\section{Experimental}

\subsection{Materials}

Vanadium oxide $\left(\mathrm{V}_{2} \mathrm{O}_{5}\right.$, Sigma Aldrich), cobalt chloride $\left(\mathrm{CoCl}_{2}\right.$, Sigma Aldrich), multiwalled carbon nanotubes (MWCNT-HP 
150, Bayer Material Science), acetonitrile (MeCN, Fisher Chemical), cyclohexane $\left(\mathrm{C}_{6} \mathrm{H}_{6}\right.$, Sigma Aldrich), and $30 \%$ aqueous solution of hydrogen peroxide $\left(\mathrm{H}_{2} \mathrm{O}_{2}\right.$, Sigma Aldrich) were handled under normal ambient conditions without any purification prior to use.

\subsection{Preparation and characterization of dispersed catalysts}

$\mathrm{V}_{2} \mathrm{O}_{5}$ and/or $\mathrm{CoCl}_{2}$ with different molar ratios (total mass: $200 \mathrm{mg}$ ) were directly placed in a PM100/200 Retsch GmbH planetary ball mill equipped with a $50 \mathrm{~mL}$ bowl and mechanically ground with 10 stainless steel balls of $10 \mathrm{~mm}$ diameter for $1 \mathrm{~h}$ similar to the procedures described before. ${ }^{5}$ Multiwalled carbon nanotube (CNT) additives (loadings from 0.1 to $5 \mathrm{wt} \%$ or $c a$. $100-1000$ metal-per-carbon molar ratios) were also added in some cases to prepare catalytic composites. $^{5 a, c}$ The milling frequency was $450 \mathrm{rpm}$, with rotational inversions every 5 minutes. All the dispersed mixtures were prepared by dry milling. The dispersed materials were characterized by scanning electron microscopy (SEM) using JEOL $7001 \mathrm{~F}$ equipment. The composition of the $(1: 1) \mathrm{CoCl}_{2}-\mathrm{V}_{2} \mathrm{O}_{5}$ ball milled mixture was studied by X-ray Photoelectron Spectroscopy (XPS) using a XSAM800 spectrometer from Kratos. The characterization of each individual salt was reported previously. ${ }^{5 a}$ The operating and recording conditions as well as the details of data treatment were as described in ref. $5 a$. The sensitivity factors used for the mixture analysis were those of the software library when the radiation source is an aluminum anode.

\subsection{Catalytic studies}

$100 \mu \mathrm{mol}$ of catalyst (dispersed with or without ball milling treatment), $3 \mathrm{~mL} \mathrm{MeCN}$ (solvent) and $5 \mathrm{mmol}(540 \mu \mathrm{L})$ cyclohexane (substrate) were introduced into a pyrex tube. Subsequently, $10 \mathrm{mmol}$ of a $30 \%$ aqueous hydrogen peroxide solution (oxidant) was added. For the experiments under microwave radiation, the tube was sealed and placed in a microwave reactor and the system was stirred under $5 \mathrm{~W}$ at $30{ }^{\circ} \mathrm{C}$ for 1 or $2 \mathrm{~h}$. CAUTION: Mixtures of $\mathrm{H}_{2} \mathrm{O}_{2}$ with organic compounds are potentially explosive! At the end of the reaction, $10 \mathrm{~mL}$ of diethyl ether (for the substrate and organic product extraction) and $90 \mu \mathrm{L}$ of cycloheptanone (internal standard) were added. The final mixture was stirred for $10 \mathrm{~min}$ and finally a sample $(1 \mu \mathrm{l})$ was taken from the organic phase and analyzed by GC. Following a method developed by Shul'pin, ${ }^{6}$ an excess of triphenylphosphine $\left(\mathrm{PPh}_{3}\right)$ was added prior to the GC analysis, to reduce the cyclohexyl hydroperoxide formed to the corresponding alcohol and the hydrogen peroxide to water. The reported and below-discussed cyclohexanone/cyclohexanol (ONE/OL) ratio corresponds to the cyclohexanone/(cyclohexanol + cyclohexyl peroxide) $[\mathrm{ONE} /(\mathrm{OL}+\mathrm{ROOH})]$ ratio. Blank experiments were performed using different amounts of $\mathrm{H}_{2} \mathrm{O}_{2}$ and confirmed that no cyclohexane oxidation product was obtained in the absence of a metal catalyst.

For performing the oxidation of cyclohexane exclusively under mechanochemical (ball-milling) treatment, the calcu- lated amount of the catalytic material was directly added to the grinding bowl of the ball mill, whereafter the substrate (cyclohexane) and the oxidant $\left(\mathrm{H}_{2} \mathrm{O}_{2}, 30 \%\right.$ aq. solution) were added and the reaction was performed as described above, but without the addition of the NCMe solvent.

Gas chromatographic measurements were carried out using a FISONS Instruments GC 8000 series gas chromatograph with a FID detector and a capillary column (DB-WAX, column length: $30 \mathrm{~m}$; internal diameter: $0.32 \mathrm{~mm}$ ) ( $\mathrm{He}$ as the carrier gas) and the Jasco-Borwin v.1.50 software. The temperature of injection was $240{ }^{\circ} \mathrm{C}$. The initial temperature of the column was maintained at $100^{\circ} \mathrm{C}$ for $1 \mathrm{~min}$, then increased at a rate of $10^{\circ} \mathrm{C} \min ^{-1}$ up to $180{ }^{\circ} \mathrm{C}$ and the column was maintained at this temperature for $1 \mathrm{~min}$. The attribution of the peaks was made by comparison with the chromatograms of genuine samples.

\section{Results and discussion}

\subsection{Preparation and characterization of the catalysts}

The dispersed catalytic materials were prepared by the mechanical treatment of $\mathrm{V}_{2} \mathrm{O}_{5}$ and/or $\mathrm{CoCl}_{2}$ in a planetary ball reactor ${ }^{7}$ as indicated above. The choice of these systems was made based on our previous studies ${ }^{3,5}$ and the literature data. $^{2,4}$ According to SEM images (Fig. 1), the produced materials consist of non-uniform microcrystallites with different shapes and particle sizes above $1 \mu \mathrm{m}$ for the ball milled $\mathrm{CoCl}_{2}$ (Fig. 1a), $\mathrm{V}_{2} \mathrm{O}_{5}$ (Fig. 1b), and the $\mathrm{CoCl}_{2}-\mathrm{V}_{2} \mathrm{O}_{5}$ $(3: 1) \$$ mixture (Fig. 1c and d). More details of the morphology and structure of the prepared catalysts can be found in our previous papers devoted to the preparation and study of related dispersed materials. ${ }^{5}$

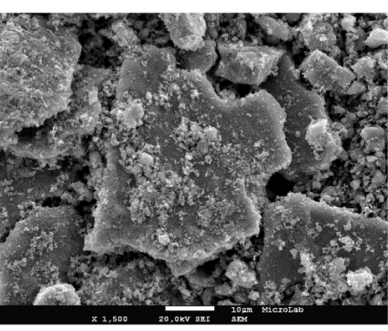

(a)

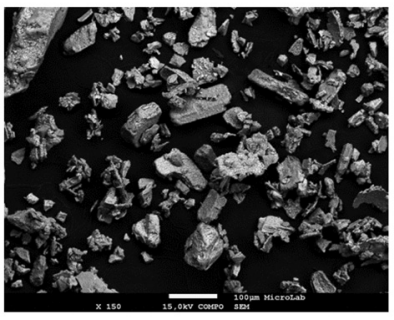

(c)

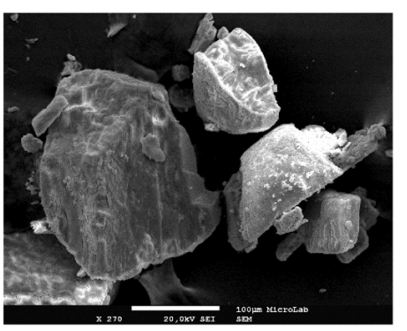

(b)

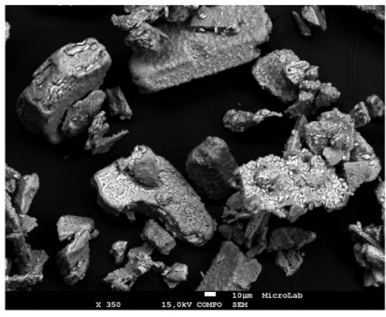

(d)
Fig. 1 SEM images: (a) ball-milled $\mathrm{CoCl}_{2}$, scale, $10 \mu \mathrm{m}$; (b) ball-milled $\mathrm{V}_{2} \mathrm{O}_{5}$, scale, $100 \mu \mathrm{m}$; (c) $\mathrm{CoCl}_{2}-\mathrm{V}_{2} \mathrm{O}_{5}$ (3:1), scale, $100 \mu \mathrm{m}$; (d) $\mathrm{CoCl}_{2}-$ $\mathrm{V}_{2} \mathrm{O}_{5}(3: 1)$, scale, $10 \mu \mathrm{m}$. 
XPS shows that after ball milling the composition of each salt is nearly the same as that before mixing.

Fig. 2 shows the relevant XPS regions of the ball milled mixture $\mathrm{CoCl}_{2}-\mathrm{V}_{2} \mathrm{O}_{5}(1: 1)$. In Table 1 , the atomic ratio $\mathrm{Co} / \mathrm{Cl}>$ 0.5 suggests that the mixture is composed not only of cobalt chloride, but also of some cobalt hydroxides and/or oxyhydroxides, as in $\mathrm{CoCl}_{2} \cdot{ }^{5 a}$ Actually, the main peaks in Co $2 \mathrm{p}_{3 / 2}$, centred at $782.2 \pm 0.2 \mathrm{eV}$ and $783.9 \pm 0.2 \mathrm{eV}$ (Fig. 2a), are both assigned to $\mathrm{Co}^{2+}$ in $\mathrm{CoCl}_{2}$ and in $\mathrm{Co}(\mathrm{OH})_{2}$ but, most probably, included in powder phases with different resistivities. ${ }^{5 a}$ Such an effect, which was also observed for a $\mathrm{CoCl}_{2}-\mathrm{Fe}_{2} \mathrm{O}_{3}$ mixture studied previously, ${ }^{5 a}$ is also detected in the $\mathrm{Cl} 2 \mathrm{p}$ region: $\mathrm{Cl} 2 \mathrm{p}$ was fitted with two doublets (the main $\mathrm{Cl} 2 \mathrm{p}_{3 / 2}$ component being centred at $\sim 200.3 \mathrm{eV}$ ) revealing the presence of some differential charge resulting from mixed phases with different conductivities and/or important contact potential between powder particles. V $2 \mathrm{p}$, detected next to $\mathrm{O} 1 \mathrm{~s}$, with $\mathrm{V} 2 \mathrm{p}_{3 / 2}$ centred at $517.6 \mathrm{eV} \pm 0.1 \mathrm{eV}$, confirms that the vanadium oxide is quite stable, maintaining the stoichiometry of the starting material $\left(\mathrm{V}_{2} \mathrm{O}_{5}{ }^{5 a}\right)$ even after ball milling (Table 1). $\mathrm{O}$ 1s was fitted with three peaks: the main peak, centred at $530.6 \mathrm{eV}$, is assigned to oxygen in $\mathrm{V}_{2} \mathrm{O}_{5}$ (it is not detected in $\mathrm{CoCl}_{2}{ }^{5 a}$ ), and the other two peaks, at the high binding energy side, with low relative intensities, centred at 532.4 and $534 \mathrm{eV}$, are assigned to oxygen bound to cobalt (as showed by the quantitative analysis) and to some oxidized carbonaceous contamination. ${ }^{8}$

\subsection{Catalytic studies}

To choose the most appropriate catalytic material for further comparative studies, several ball-milled $\mathrm{CoCl}_{2}-\mathrm{V}_{2} \mathrm{O}_{5}$ mixtures with different metal ratios $(1: 1,3: 1$ and $1: 3)$ and starting $\mathrm{V}_{2} \mathrm{O}_{5}$ and $\mathrm{CoCl}_{2}$ samples (also dispersed in the ball mill under the same conditions) were screened for the peroxidative microwave-assisted oxidation of cyclohexane with $\mathrm{H}_{2} \mathrm{O}_{2} \quad(30 \%$ aq. solution) (Table 2). CNTs were also added in several cases since our previous studies ${ }^{5}$ demonstrated that their addition can provide a significant promoting effect. In all cases, the formation of a mixture of cyclohexyl hydroperoxide $(\mathrm{CyOOH}$,
Table 1 XPS quantitative results for the precursor salts (studied in ref. $5 a)$ and the mixed material $\mathrm{CoCl}_{2}-\mathrm{V}_{2} \mathrm{O}_{5}(1: 1)$

\begin{tabular}{lll}
\hline & $\mathrm{Co} / \mathrm{Cl}$ & $\mathrm{O}_{530.6} / \mathrm{V}$ \\
\hline $\mathrm{CoCl}_{2}$ & 0.8 & \\
$\mathrm{~V}_{2} \mathrm{O}_{5}$ & & 2.5 \\
$\mathrm{CoCl}_{2}-\mathrm{V}_{2} \mathrm{O}_{5}$ & 0.9 & 2.4
\end{tabular}

primary product), cyclohexanol $(\mathrm{CyOH})$ and cyclohexanone (CyO) (Scheme 1a and Fig. S1 $\dagger$ ) was observed. The alcohol and ketone are the major products upon the metal-assisted decomposition of $\mathrm{CyOOH}$, the formation of the alcohol being promoted by the reduction of $\mathrm{CyOOH}$ with triphenylphosphine $\left(\mathrm{PPh}_{3}\right)\left(\right.$ Scheme 1b). ${ }^{6}$

The $\mathrm{CoCl}_{2}-\mathrm{V}_{2} \mathrm{O}_{5}(3: 1)$ ball-milled mixture showed a remarkable activity under the established experimental conditions, resulting in a $43 \%$ (in relation to the substrate) overall yield of cyclohexanol and cyclohexanone with a total turnover number (TON) of 22 (22 moles of products per mole of metal compound) (entry 2, Table 2) and a selectivity of up to $93 \%$ for (cyclohexanol + cyclohexyl peroxide), after $1 \mathrm{~h}$ of reaction at $30{ }^{\circ} \mathrm{C}$ and under microwave irradiation $(5 \mathrm{~W})$. In the tested catalytic systems, the cyclohexanone/cyclohexanol ratio is in the range of $0.07-0.7$ (Table 2), whereas in the industrial processes ${ }^{4,9}$ the ratio generally falls in the $0.5-0.7$ range. The common high predominance of cyclohexanol over cyclohexanone in our systems suggests the presence of cyclohexyl hydroperoxide in the reaction mixture as a primary oxidation product of cyclohexane which, after treatment with $\mathrm{PPh}_{3}$ (see the Experimental part), gives the corresponding alcohol in a relatively large quantity ${ }^{6}$ (Scheme $\left.1 \mathrm{~b}\right)$.

The use of a ball milled $\mathrm{CoCl}_{2}-\mathrm{V}_{2} \mathrm{O}_{5}$ mixture $(3: 1)$ resulted in a marked yield increase relative to the use of any starting component, from $1.3 \%$ for $\mathrm{CoCl}_{2}$ or $13.5 \%$ for $\mathrm{V}_{2} \mathrm{O}_{5}$ to $43.3 \%$ for $\mathrm{CoCl}_{2}-\mathrm{V}_{2} \mathrm{O}_{5}(3: 1)$ (entries 11, 10 and 2, respectively, Table 2). The achieved yield for the $\mathrm{CoCl}_{2}-\mathrm{V}_{2} \mathrm{O}_{5}(3: 1)$ mixture (43.3\% overall yield), with a concomitant high selectivity, is much higher than that (ca. 4-6\%) of the industrial process ${ }^{4,9}$
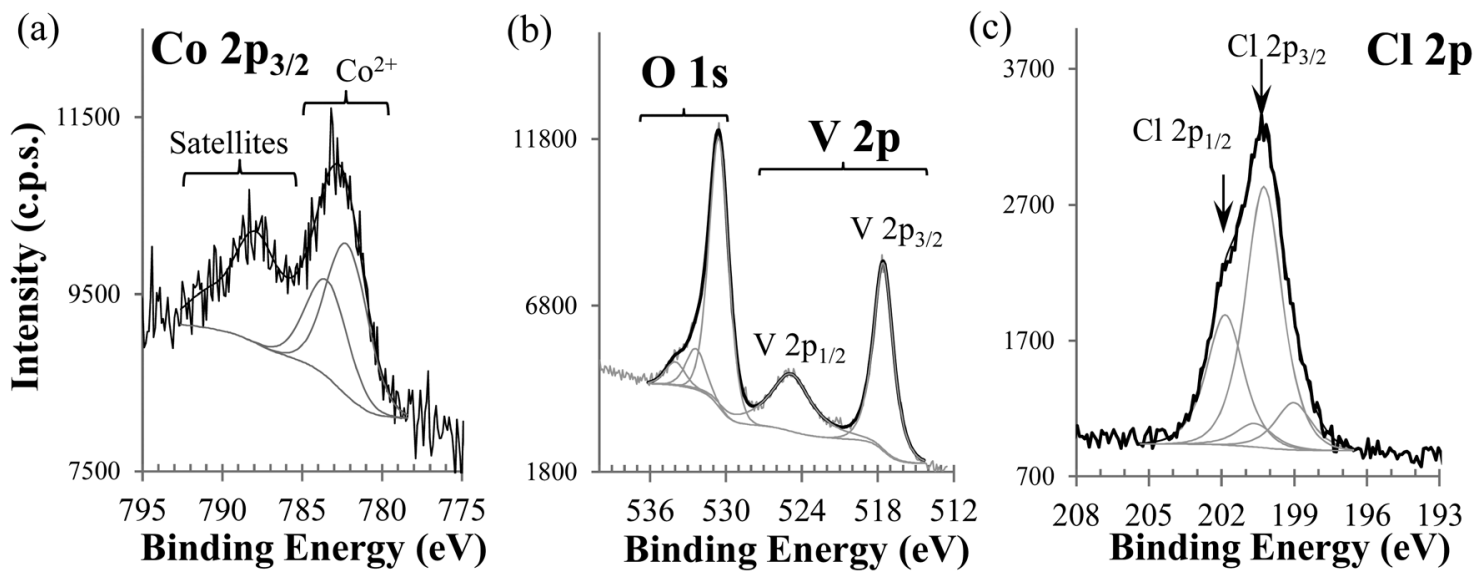

Fig. $2 \mathrm{CoCl}_{2}-\mathrm{V}_{2} \mathrm{O}_{5}(1: 1)$ XPS regions: (a) $\mathrm{Co} 2 \mathrm{p}_{3 / 2}$; (b) $\mathrm{O}$ 1s and $\mathrm{V} 2 \mathrm{p}$; and (c) $\mathrm{Cl} 2 \mathrm{p}$. 
Table $2 \mathrm{MW}$-assisted peroxidative oxidation of cyclohexane, over ball milled $\mathrm{CoCl}_{2}-\mathrm{V}_{2} \mathrm{O}_{5}$ mixtures, $\mathrm{V}_{2} \mathrm{O}_{5}$ or $\mathrm{CoCl}_{2}$ as catalysts ${ }^{a}$

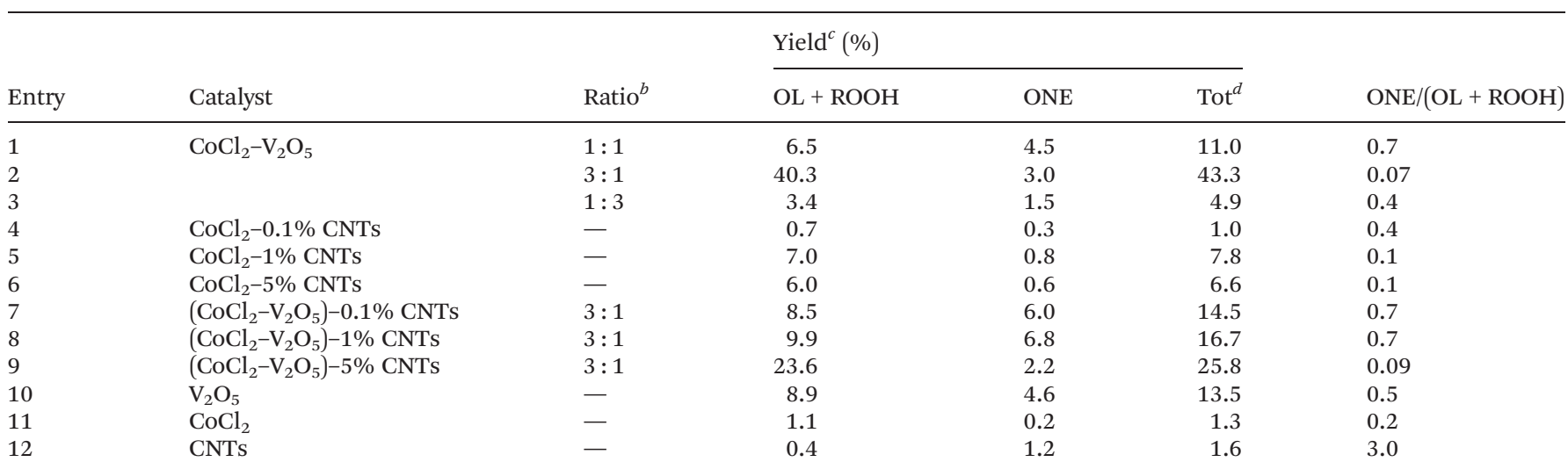

${ }^{a}$ Reaction conditions (BM + MW): Cyclohexane ( $\left.5.0 \mathrm{mmol}\right), 100 \mu \mathrm{mol}$ of catalyst ( $2 \mathrm{~mol} \%$ vs. substrate, after ball mill treatment, BM), NCMe ( $3 \mathrm{~mL}), 30 \%$ aq. $\mathrm{H}_{2} \mathrm{O}_{2}$ solution (10 mmol), $1 \mathrm{~h}, 30^{\circ} \mathrm{C}$, microwave (MW) irradiation ( $5 \mathrm{~W}$ ); yield and TON determined by gas chromatography upon treatment with $\mathrm{PPh}_{3}$ (see the text). ${ }^{b}$ Molar ratio between the components of the prepared catalyst mixture. ${ }^{c}$ Molar yield (\%) based on the substrate, i.e. moles of products [cyclohexanol (OL) and cyclohexanone (ONE)] per 100 moles of cyclohexane. ${ }^{d}$ Total yield $=$ moles of products $[\mathrm{OL}+\mathrm{ONE}] / 100$ moles of $\mathrm{C}_{6} \mathrm{H}_{12}$. CNTs = multiwalled carbon nanotubes.

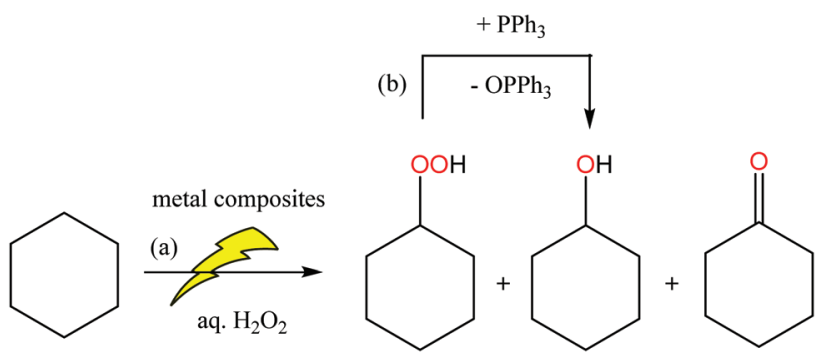

Scheme 1 Microwave-assisted peroxidative (with $\mathrm{H}_{2} \mathrm{O}_{2}$ ) oxidation of cyclohexane.

in spite of the mild reaction conditions used and is comparable to those obtained ${ }^{3 h}$ in the presence of $\mathrm{Fe}(\mathrm{III})-\mathrm{Cr}(\mathrm{III})$ hydroxides (up to $45 \%$ ). However, the latter catalytic system requires the use of a strong acid $\left(\mathrm{HNO}_{3}\right){ }^{3 h}$ The combination of such a considerable yield achieved in a short reaction time $(1 \mathrm{~h})$ under mild conditions $\left(30^{\circ} \mathrm{C}, 5 \mathrm{~W}\right)$ and without any additive is a rare example which points out an outstanding activity of the catalytic system based on the $\mathrm{CoCl}_{2}-\mathrm{V}_{2} \mathrm{O}_{5}(3: 1)$ binary mixture prepared by ball milling treatment.

The presence of CNT additives affects differently the catalytic activity of the studied systems (Table 2). Thus, for $\mathrm{CoCl}_{2}$, a yield improvement is observed when 1 and 5 wt $\%$ of CNTs have been used, namely from $1.3 \%$ in the absence of CNTs (entry 11, Table 2) to 7.8 and $6.6 \%$, (entries 5 and 6, Table 2, respectively). However, for the $\mathrm{CoCl}_{2}-\mathrm{V}_{2} \mathrm{O}_{5}$ systems, the yield decreases in the presence of CNTs (entries 7-9, Table 2). This hampering effect of the CNTs contrasts with a few other cases where the presence of such additives can result in a significant improvement in the catalytic performance. ${ }^{5}$

In order to compare the influence of MW and mechanochemical BM energy inputs, we have chosen the most active catalytic material, i.e. the $\mathrm{CoCl}_{2}-\mathrm{V}_{2} \mathrm{O}_{5}(3: 1)$ mixture. With this catalytic material, some tests were carried out using the follow-

\begin{tabular}{|c|c|c|}
\hline $\begin{array}{c}\text { CATALYST } \\
\text { PREPARATION }\end{array}$ & CATALYSIS & CODE \\
\hline & & \\
\hline & & \\
\hline
\end{tabular}

Scheme 2 Comparison of microwave and mechanochemical energy inputs.

ing combinations (Scheme 2): (i) preparation of the catalyst by ball milling $(1 \mathrm{~h})$ and its subsequent application in the peroxidative oxidation of cyclohexane under MW irradiation $\left(1 \mathrm{~h}, 30^{\circ} \mathrm{C}\right)(\mathrm{BM}+\mathrm{MW})$; (ii) conducting the oxidation reaction under MW irradiation without any BM treatment of the catalyst before use (MW) and (iii) conducting the catalyst preparation and the oxidation reaction by ball milling in one pot without MW irradiation $(\mathrm{BM}+\mathrm{BM})$. The results are presented in Table 3.

The first method (BM + MW), which is the one in which the catalyst is prepared by ball milling and then used in the peroxidative oxidation of cyclohexane under MW irradiation, results in the highest overall product yield (43\%, entry 1 , Table 3 ) with the maximum $93 \%$ selectivity towards cyclohexanol over cyclo- 
Table 3 Peroxidative oxidation of cyclohexane over the $\mathrm{CoCl}_{2}-\mathrm{V}_{2} \mathrm{O}_{5}$ $(3: 1)$ catalyst using MW and BM treatments ${ }^{a}$

\begin{tabular}{llllrr}
\hline & & & \multicolumn{2}{l}{ Yield $^{b}(\%)$} \\
\cline { 5 - 6 } Entry & Method & $\begin{array}{l}\text { Reaction } \\
\text { time (h) }\end{array}$ & OL & ONE & Total $^{c}$ \\
\hline $1^{d}$ & BM + MW & 1 & 40.3 & 3.0 & 43.3 \\
$2^{e}$ & MW & 1 & 20.9 & 9.5 & 30.4 \\
$3^{e}$ & MW & 2 & 29.1 & 10.8 & 39.9 \\
$4^{f}$ & BM + BM & 1 & 22.4 & 6.2 & 28.6 \\
$5^{f}$ & BM + BM & 2 & 26.6 & 5.5 & 32.1 \\
$6^{g}$ & BM & 1 & 0.2 & 0.1 & 0.3 \\
$7^{h}$ & BM & 1 & 5.9 & 0.7 & 6.6 \\
$8^{i}$ & - & 1 & 0.7 & 0.4 & 1.1
\end{tabular}

${ }^{a}$ Reaction conditions: $5 \mathrm{mmol}$ of substrate, $100 \mu \mathrm{mol}$ metal composite ( $2 \mathrm{~mol} \%$ vs. substrate), NCMe ( $3 \mathrm{~mL}$ ) (only for the BM + MW and MW methods, entries 1-3), $10 \mathrm{mmol}$ of $\mathrm{H}_{2} \mathrm{O}_{2}$ (aq. $30 \%$ ), $30{ }^{\circ} \mathrm{C}$, microwave irradiation $(5 \mathrm{~W}) .{ }^{b}$ Molar yield $(\%)$ based on the substrate, i.e. moles of product per $100 \mathrm{~mol}$ of substrate determined by GC. ${ }^{c}$ Total yield $=$ moles of products [cyclohexanol $(\mathrm{OL})+$ cyclohexanone $(\mathrm{ONE})] / 100 \mathrm{~mol}$ of $\mathrm{C}_{6} \mathrm{H}_{12}$, determined by GC after treatment with $\mathrm{PPh}_{3} .{ }^{d} \mathrm{BM}+\mathrm{MW}=$ preparation of the catalyst with ball milling treatment (BM) and catalysis under MW irradiation. ${ }^{e} \mathrm{MW}=$ preparation of the catalyst without ball milling treatment, by manual grinding, and used directly in peroxidative oxidation under $\mathrm{MW}$ irradiation. ${ }^{f} \mathrm{BM}+\mathrm{BM}=$ catalyst preparation and catalytic reaction exclusively by ball milling treatment, without MW irradiation and without the NCMe solvent. ${ }^{g}$ Oxidation reaction performed by ball milling without any catalyst. ${ }^{h}$ Catalytic reaction performed with a ball milled catalyst and without microwave irradiation. ${ }^{i}$ Catalytic reaction performed with a catalyst mixture used without previous ball milling treatment (mixed manually) and without microwave irradiation.

hexanone. Conducting the oxidation reaction under MW irradiation under the same conditions but without any ball milling treatment of the catalyst before use (MW method) gives a lower total yield of $30.4 \%$ with a $69 \%$ selectivity towards cyclohexanol over cyclohexanone (entry 2, Table 3).

The results obtained in the third procedure $(\mathrm{BM}+\mathrm{BM})$ (entries 4 and 5, Table 3) are rather interesting, since the catalyst preparation and the catalytic reaction were assisted only by ball milling, without any additive and in the absence of any organic solvent, leading to high overall yields of 28.6 and $32.1 \%$ after 1 or $2 \mathrm{~h}$ of reaction, respectively, at room temperature.

Additionally, the oxidation reactions were performed in the absence of microwave irradiation (entries 6-8, Table 3) using catalytic mixtures with (entry 6, Table 3 ) and without (entry 8 , Table 3) previous ball milling treatment. In both cases, the yields were quite low (6.6 and $1.1 \%$, respectively), demonstrating once again the importance of MW irradiation in the catalytic reaction and the advantage of using ball milled catalytic mixtures as catalysts. The oxidation of cyclohexane was also performed exclusively by ball milling without the addition of metal composites and residual amounts of the product were detected (entry 7, Table 3).

Among the reported vanadium or cobalt metal catalysts applied for alkane oxidations with $\mathrm{H}_{2} \mathrm{O}_{2}$, the product yields achieved herein are remarkable. ${ }^{3,10}$ Besides this, the catalytic systems under study involve greener reaction conditions, since they do not involve any additive or organic solvent (in the case of the sole use of mechanochemical treatment, $\mathrm{BM}+\mathrm{BM}$ method) and perform well at room temperature in a short reaction time $(1 \mathrm{~h})$. Compared to our catalysts, the binuclear oxidovanadium(v) complex bearing an $\mathrm{NO}_{2}$-donor Schiff base ligand $\left[\{\mathrm{VO}(\mathrm{EtO})(\mathrm{EtOH})\}_{2}\left(1 \kappa^{2} \mathrm{O}, \kappa N: 2 \kappa^{2} \mathrm{O}, \kappa N-\mathrm{L}\right)\right] \cdot 2 \mathrm{H}_{2} \mathrm{O}\left(\mathrm{H}_{4} \mathrm{~L}=\right.$ bis(2-hydroxybenzylidene)oxalohydrazonic acid), a homogeneous catalyst for the oxidation of gaseous and liquid alkanes by aqueous $\mathrm{H}_{2} \mathrm{O}_{2}$ under mild conditions, leads to $27.6 \%$ yield of oxygenates (cyclohexanol + cyclohexanone) in the presence of the acid co-catalyst 2-pyrazinecarboxylic acid (PCA), using $\mathrm{H}_{2} \mathrm{O}_{2}(50 \%$ aqueous solution) as an oxidant, in acetonitrile, at $50{ }^{\circ} \mathrm{C}$ and after $4 \mathrm{~h}$ of reaction. ${ }^{11}$

\section{Conclusions}

Cobalt and/or vanadium dispersed catalytic materials were prepared by a simple and solvent-free mechanochemical method, i.e., ball-milling. The prepared heterometallic systems act as efficient catalysts for the peroxidative oxidation (with aq. $\mathrm{H}_{2} \mathrm{O}_{2}$ ) of cyclohexane to cyclohexanol and cyclohexanone, under mild conditions. The microwave and mechanochemical energy inputs were compared and it was shown that the most effective combination comprises the catalytic reaction performed under microwave irradiation and using the $\mathrm{CoCl}_{2}-\mathrm{V}_{2} \mathrm{O}_{5}(3: 1)$ catalyst prepared mechanochemically. However, the catalyst preparation and the catalytic reaction can be achieved in one-pot at room temperature and by using exclusively the mechanochemical BM energy input with considerable yields of 29 and 32\% after 1 and $2 \mathrm{~h}$, respectively. Hence, mechanochemical methods appear to be quite promising in the field of alkane functionalization and deserve to be further explored for a variety of catalytic systems and reactions.

\section{Conflicts of interest}

There are no conflicts to declare.

\section{Acknowledgements}

Financial support from the Fundação para a Ciência e a Tecnologia, Portugal (fellowships SFRH/BPD/90883/2012 to A. P. C. R., SFRH/BPD $/ 108338 / 2015$ to A. M. F. and the "Investigador 2013" contract to M. N. K. IF/01270/2013/ CP1163/CT0007 project, UID/QUI/00100/2013, PTDC/QEQ-QIN/ $3967 / 2014$ and UID/NAN/50024/2013 projects) and from the Instituto Politécnico de Lisboa (MechSynCat Project-Concurso Anual de IDI\&CA, 710044/2016) is acknowledged.

\section{References}

$\ddagger$ Here and further molar ratios are indicated.

1 (a) A. Bruckmann, A. Krebs and C. Bolm, Green Chem., 2008, 10, 1131-1141; (b) R. B. Nasir Baig and R. S. Varma, 
Chem. Soc. Rev., 2012, 41, 1559-1584; (c) S. L. James, C. J. Adams, C. Bolm, D. Braga, P. Collier, T. Frisčǐć, F. Grepioni, K. D. M. Harris, G. Hyett, W. Jones, A. Krebs, J. Mack, L. Maini, A. G. Orpen, I. P. Parkin, W. C. Shearouse, J. W. Steedk and D. C. Waddelli, Chem. Soc. Rev., 2012, 41, 413-447; (d) A. Stolle, T. Szuppa, S. E. S. Leonhardt and B. Ondruschka, Chem. Soc. Rev., 2011, 40, 2317-2329; (e) R. Schmidt, R. Thorwirth, T. Szuppa, A. Stolle, B. Ondruschka and H. Hopf, Chem. Eur. J., 2011, 17, 8129-8138; (f) J. Yu, Z. Jiang and W. Su, Cross Dehydrogenative Coupling Reactions by Ball Milling, in Ball Milling Towards Green Synthesis: Applications, Projects, Challenges, ed. A. Stolle and B. C. Ranu, RSC, Cambridge, 2015, pp. 96-113; (g) R. Schmidt, H. M. Scholze and A. Stolle, Int. J. Ind. Chem., 2016, 7, 181-186.

2 (a) Microwave Assisted Organic Synthesis, ed. J. P. Tierney and P. Lidstrom, Blackwell, UK, 2005; (b) Y. Y. Karabach, M. N. Kopylovich, K. T. Mahmudov and A. J. L. Pombeiro, Microwave-assisted catalytic oxidation of alcohols to carbonyl compounds (Chapter 18), in Advances in Organometallic Chemistry and Catalysis (The Silver/Gold Jubilee ICOMC Celebratory Book), ed. A. J. L. Pombeiro, J. Wiley \& Sons, 2014, pp. 233-246.

3 (a) A. J. L. Pombeiro, Toward functionalization of alkanes under environmentally benign conditions (Chapter 2), in Organometallic Chemistry and Catalysis (The Silver/Gold Jubilee ICOMC Celebratory Book), ed. A. J. L. Pombeiro, J. Wiley \& Sons, 2014, pp. 15-25; (b) A. P. C. Ribeiro, L. M. D. R. S. Martins and A. J. L. Pombeiro, Green Chem., 2017, 19, 1499-1501; (c) L. M. D. R. S. Martins and A. J. L. Pombeiro, Eur. J. Inorg. Chem., 2016, 22362252; (d) O. V. Nesterova, M. N. Kopylovich and D. S. Nesterov, RSC Adv., 2016, 6, 93756-93767; (e) M. N. Kopylovich, M. J. Gajewska, K. T. Mahmudov, M. V. Kirillova, P. J. Figiel, M. F. C. Guedes da Silva, B. Gil-Hernandez, J. Sanchiz and A. J. L. Pombeiro, New J. Chem., 2012, 36, 1646-1654; (f) T. C. O. Мac Leod, M. N. Kopylovich, M. F. C. Guedes da Silva, K. T. Mahmudov and A. J. L. Pombeiro, Appl. Catal., A, 2012, 439, 15-23; $(g)$ M. N. Kopylovich, T. C. O. Mac Leod, M. Haukka, G. I. Amanullayeva, K. T. Mahmudov and A. J. L. Pombeiro, J. Inorg. Biochem., 2012, 115, 72-77; (h) M. N. Kopylovich, A. M. Kirillov, A. K. Baev and A. J. L. Pombeiro, J. Mol. Catal. A: Chem., 2003, 206, 163-178.

4 (a) Ullmann's Encyclopedia of Industrial Chemistry, WileyVCH, Weinheim, 6th edn, 2002; (b) U. Schuchardt, D. Cardoso, R. Sercheli, R. Pereira, R. S. da Cruz, M. C. Guerreiro, D. Mandelli, E. V. Spinacé and E. L. Pires, Appl. Catal., A, 2001, 211, 1-17; (c) K. Weissermel and H. J. Arpe, Industrial Organic Chemistry, VCH Press, Weinheim, 2nd edn, 1993.

5 (a) E. C. B. A. Alegria, E. Fontolan, A. P. C. Ribeiro, M. N. Kopylovich, C. Domingos, A. M. Ferraria, R. Bertani, A. M. Botelho do Rego and A. J. L. Pombeiro, Mat. Today Chem., 2017, 52-62; (b) E. Fontolan, E. C. B. A. Alegria, A. P. C. Ribeiro, M. N. Kopylovich, R. Bertani and A. J. L. Pombeiro, Inorg. Chim. Acta, 2017, 455, 653-658; (c) A. P. C. Ribeiro, E. Fontolan, E. C. B. A. Alegria, M. N. Kopylovich, R. Bertani and A. J. L. Pombeiro, J. Mol. Catal. A: Chem., 2017, 426, 557-563.

6 (a) G. B. Shul'pin, C. R. Chim., 2003, 6, 163-178; (b) G. B. Shul'pin, Y. N. Kozlov, L. S. Shul'pina, A. R. Kudinov and D. Mandelli, Inorg. Chem., 2009, 48, 10480-10482; (c) G. B. Shul'pin, Y. N. Kozlov, L. S. Shul'pina and P. V. Petrovskiy, Appl. Organomet. Chem., 2010, 24, 464-472; (d) G. B. Shul'pin, J. Mol. Catal. A: Chem., 2002, 189, 39-66; (e) G. B. Shul'pin, Dalton Trans., 2013, 42, 12794-12818.

7 (a) J. Wang, S. Ganguly, S. Sabyasachi, N. D. Browning and S. M. Kauzlarich, Polyhedron, 2013, 58, 156-161; (b) Z. Wronski, R. A. Varin, C. Chiu, T. Czujko and A. Calka, J. Alloys Compd, 2007, 434-435, 743-746; (c) T. D. Shen, C. C. Koch, T. L. McCormick, R. J. Nemanich, J. Y. Huang and J. G. Huang, J. Mater. Res., 1995, 10, 139-148.

8 G. Beamson and D. Briggs, High Resolution XPS of Organic Polymers, the Scienta ESCA300 Database, Wiley, New York, 1992.

9 A. P. Pokutsa, R. B. Sheparovich, A. B. Zaborovskii and V. I. Kopylets, Kinet. Catal., 2002, 43(5), 69-697.

10 (a) M. Sutradhar, E. C. B. A. Alegria, M. F. C. Guedes da Silva, L. M. D. R. S. Martins and A. J. L. Pombeiro, Molecules, 2016, 21, 425-437; (b) T. F. S. Silva, E. C. B. A. Alegria, L. M. D. R. S. Martins and A. J. L. Pombeiro, Adv. Synth. Catal., 2008, 350, 706-716.

11 S. Gupta, M. V. Kirillova, M. F. Guedes da Silva and A. J. L. Pombeiro, Appl. Catal., A, 2013, 460-461, 82-89. 